\title{
Powder Filling Method, Not Otherwise Specified
}

National Cancer Institute

\section{Source}

National Cancer Institute. Powder Filling Method, Not Otherwise Specified. NCI

Thesaurus. Code C112998.

A process that fills a dosage unit with a powder in a method not otherwise specified. 